\title{
Interaction between wastewater-sludge floc and moving ice front
}

\author{
T. Tao ${ }^{\mathrm{a}}$, X.F. Peng ${ }^{\mathrm{a}}$, D.J. Lee ${ }^{\mathrm{b}, *}$ \\ ${ }^{a}$ Thermal Engineering Department, Tsinghua University, Beijing, 100084, China \\ ${ }^{\mathrm{b}}$ Department of Chemical Engineering, National Taiwan University, Taipei, 10617 Taiwan
}

Received 8 April 2005; received in revised form 10 February 2006; accepted 14 April 2006

Available online 29 April 2006

\begin{abstract}
Freeze/thaw treatment is an effective sludge-dewatering technique. The efficiency of dewatering of freeze/thawed sludge declines as the approaching ice front engulfs flocs at a high freezing rate. The forces exerted on a wastewater-sludge floc by the approaching ice front and the surrounding fluid field determine whether the ice front engulfs the floc. Two wastewater flocs of sizes 2170 and $2240 \mu \mathrm{m}$ were hung on a cantilevered beam which underwent constant-speed freezing $\left(5\right.$ or $\left.8 \mu \mathrm{m} \mathrm{s}^{-1}\right)$. Beam deflection and the shape of sludge floc were recorded to estimate the force exerted by the ice and the elasticity of the sludge flocs. The force exerted by an approaching ice front on the floc ranged from 1.6 to $1.8 \times 10^{-6} \mathrm{~N}$, and was attributable primarily to the interaction between the gas bubbles formed between the floc and the ice front. When the ice had partly engulfed the floc, the corresponding force continuously increased as freezing continued, compressing the unfrozen part of the floc and pulling apart the network of the frozen part of the floc. The change in floc shape was tracked to estimate the interior elasticity of $0.0063-0.025 \mathrm{~N} \mathrm{~m}^{-1}$, and the elongation coefficient of $0.0030-0.0089 \mathrm{~N} \mathrm{~m}^{-1}$ for the flocs herein.
\end{abstract}

(C) 2006 Elsevier Ltd. All rights reserved.

Keywords: Freezing; Thawing; Floc; Interface; Force; Deformation

\section{Introduction}

Freeze/thaw treatment is an effective sludge-dewatering technique, and has therefore attracted substantial interest (Knocke and Trahem, 1989; Martel, 1989a,b; Vesilind and Martel, 1990; Kawasaki et al., 1991; Martel and Diener, 1991; Vesilind, 1990; Vesilind et al., 1991a,b; Kawasaki and Matsuda, 1993). Freeze/thaw treatment can considerably improve certain sludge-dewatering characteristics (Lee and Hsu, 1994), (irreversibly) change the floc structure into a more compact form (Lee, 1994), reduce the sludge-bound water content (Lee and Hsu, 1995), eliminate bacteria in the sludge (Sanin et al., 1994; Chu et al., 1999), separate oil from an oily sludge (Jean et al., 1999, 2001), and separate nanoparticles from wastewater sludge (Chang et al., 2004). This treatment process is particularly useful when natural freezing is feasible (Hellstrom and Kvarnstrom, 1997a,b). Dissolved impurities, initial concentration of solids, and curing time influence the performance of freeze/thaw treatment (Jean and Lee, 1999; Jean et al., 2000; Martel, 2000; Ormeci and Vesilind, 2001;

\footnotetext{
* Corresponding author. Tel.: +8862363 5230; fax: +88623623040.

E-mail address: djlee@ccms.ntu.edu.tw (D.J. Lee).
}

Lo et al., 2001; Lai et al., 2004). Hong et al. (1995) and Hung et al. (1997) suggested that the main action of freeze/thaw treatment is the release of some of the extracellular polymeric substances (EPS), particularly polysaccharides, from the sludge body.

The dewatering efficiency of freeze/thawed sludge is generally believed to drop as the freezing rate increases (Logsdon and Edgerley, 1971; Ezekwo et al., 1980; Randall et al., 1975; Lee and Hsu, 1994; Kawasaki and Matsuda, 1993, 1995; Wang et al., 2001). Halde (1980) adopted vertical freezing to examine the interactions between the growing ice front and the sludge flocs. Hung et al. $(1996,1997)$ and Chu et al. (1997) refined the apparatus proposed by Halde to investigate the effect of freezing rate on sludge performance, including the relationships between filterability, zone settling and floc size, and density. At a low-freezing rate, where most flocs in the sludge are repelled by the ice front and are concentrated at the far-end of the testing section, not only is the sludge filterability significantly improved but also the floc density and the morphology, and therefore the settleability, changed markedly. Parker et al. (1998a,b) and Martel (2000) claimed that these changes are caused by the mechanical squeezing of the concentrated sludge 
by the advancing ice. At a high freezing rate, at which most sludge flocs are trapped by the advancing ice, little or no dehydration of flocs is observed. At the ultrafast freezing limit, the activated sludge flocs were found to be intact following freezing and thawing (Chen et al., 2001; Chian et al., 2002). The so-called "critical freezing velocity" of a freezing sludge, if it really exists, is a critical process parameter and is determined by all the forces on an object in static equilibrium that oppose each other (Uhlman et al., 1964; Han and Hunt, 1995; Garvin and Udaykumar, 2003).

The forces that are exerted on a wastewater-sludge floc by an approaching ice front and its surrounding fluid field determine whether the ice front can engulf the floc. As discussed in the cited studies, the forces at the ice-floc interface control how ice freezes a floc. However, no information on the interactions between an approaching ice front and a wastewater-sludge floc is available. Micromanipulation has been adopted to measure floc rupture strength (Yeung and Pelton, 1996), tensile strength of biofilm (Poppele and Hozalski, 2003) and the mechanical characteristics of individual cells (Brehm-Stecher and Johnson, 2004). Tao et al. (2004) for the first time measured the force exerted on a solid polystyrene (PS) sphere of diameter $1676 \mu \mathrm{m}$, which was pushed forward by an advancing ice front that moves at $5 \mu \mathrm{m} \mathrm{s}^{-1}$. When the gas bubble nucleated and grew between the sphere and the ice front, the maximum force exerted on the sphere reached $2.42 \times 10^{-6} \mathrm{~N}$. Without the bubbles under the floc, however, the corresponding maximum force fell only to $4.0 \times 10^{-7} \mathrm{~N}$ during freezing. The presence of gas bubbles considerably increased the force exerted by an advancing ice front on a foreign particle.

This study utilized the uni-directional freezing apparatus developed by Tao et al. (2004) to perform all freezing tests. A wastewater floc was hung on an elastic beam and was frozen at a constant rate. The deflection of the cantilevered beam and the shape of the sludge floc were recorded during unidirectional freezing and thawing. The force on the floc and the elasticity of the floc were estimated from the deflection of the beam and the shape deformation, respectively, according to Hooke's Law.

\section{Experimental}

The experimental setup adopted herein resembled the one used by Tao et al. (2004) (Fig. 1), with a vertical temperature gradient. A test chamber made of optical glass of dimensions $150 \mathrm{~mm}(L) \times 50 \mathrm{~mm}(W) \times 5 \mathrm{~mm}(T)$ was immersed in the freezing pool (HAAKE C35) at $-30^{\circ} \mathrm{C}$ and the ice grew upward at a constant rate.

Two flocs were tested. Both were activated-sludge flocs collected in the recycled stream in the wastewater treatment plant of the Presidential Food Company, Taoyuan, Taiwan, which treats 250 tons of food processing wastewater daily by using primary, secondary, and tertiary treatment processes. The original sludge was flocculated in a standard baffled stirred tank using T3052, a cationic polyelectrolyte (MW of $10^{7}$ and $4.6 \mathrm{eq} \mathrm{kg}^{-1}$ surface charge) provided by Kai-Guan Chemicals, Taiwan. Flocs were collected carefully using a wide-mouth

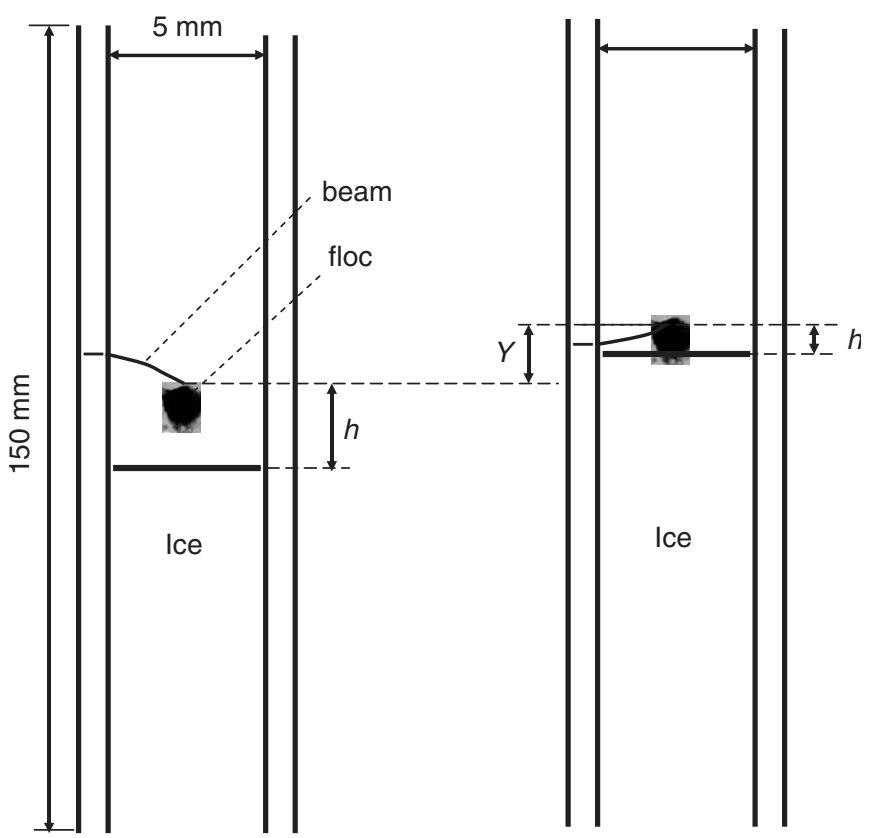

(a)

(b)

Fig. 1. The schematic of experiment setup.

pipette to reduce floc breakage. The two flocs were of similar sizes; the diameter (geometric mean of the vertical length and horizontal length) of floc 1 was $2170 \mu \mathrm{m}$ and the diameter of floc 2 was $2240 \mu \mathrm{m}$. The floc was placed on a membrane (without dehydration) and a beam gently pierced it. Two beams with Hooke's constants $(E)$ of $0.0061 \mathrm{~N} \mathrm{~m}^{-1}$ and $0.0029 \mathrm{~N} \mathrm{~m}^{-1}$ were employed herein.

A complete test involved freezing and thawing stages. During the freezing stage, the beam deflection and the morphology of the floc interior were monitored until it was completely engulfed by the ice layer. Following freezing, the direction of motion of the container was reversed to pull the container from the freezing pool. This action caused the ice to thaw at a prescribed rate. The supernatant of the sludge was the testing fluid that was used to prevent any change in the floc structure in response to a change in the aquatic environment. A digital camera, WAT WAT-505EX (Watec, Japan, 1/3 in., $768 \times 576$ pixels), with a close-up lens was used to capture the position of the beam and the shape of the floc. The images, scanned at $768 \times 576$ pixels per frame, were recorded continuously using the Orine frame grabber (Matrox, USA) and sent to a workstation where they were analyzed. The deflection of the beam $(Y)$ and the ice interface-beam distance $(h)$ were determined with a maximum error of $10 \mu \mathrm{m}$.

\section{Results and discussion}

\subsection{Floc test}

Fig. 2 shows the freezing and thawing test of floc 1 at a freezing rate of $5.0 \mu \mathrm{m} \mathrm{s}^{-1}$; the black scale bars represent $1 \mathrm{~mm}$. At this freezing rate, the advancing ice front remains flat as 


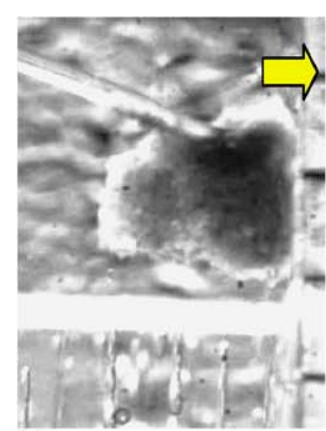

(a)

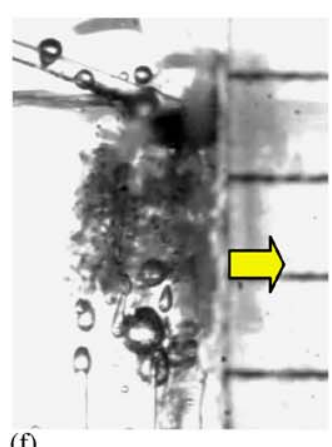

(f)

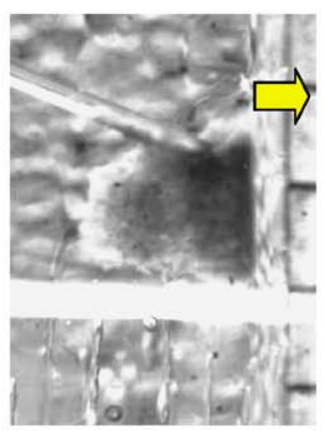

(b)

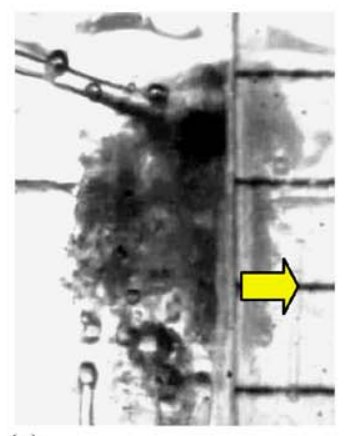

(g)
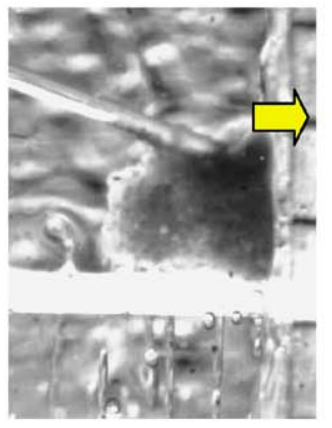

(c)

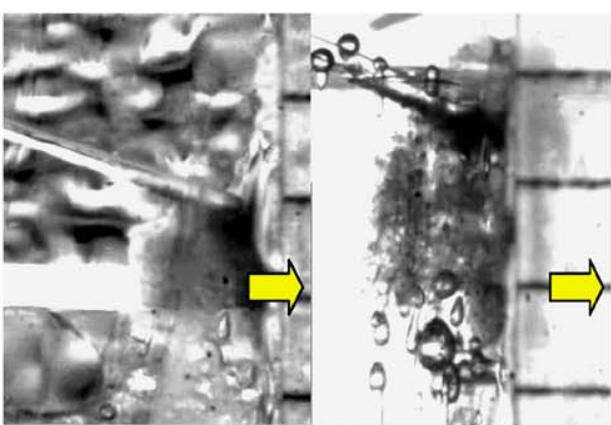

(d)

(e)

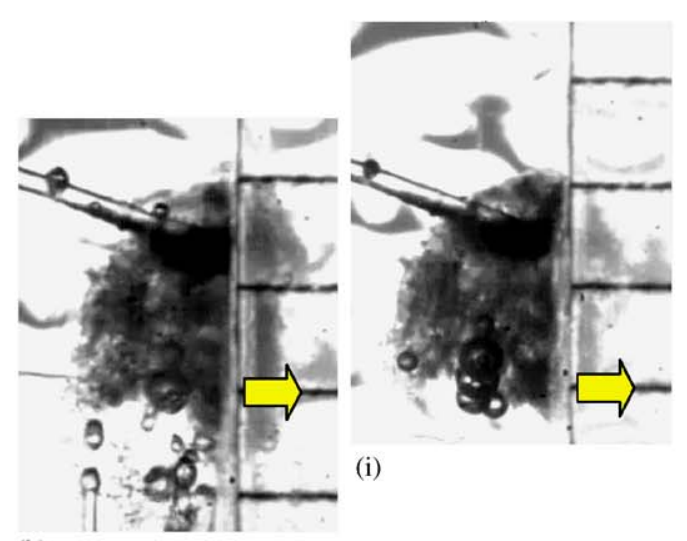

(h)

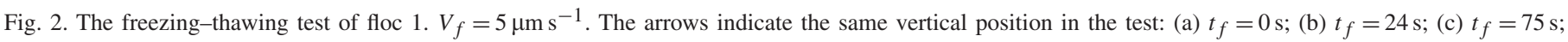
(d) $t_{f}=285 \mathrm{~s}$; (e) frozen; (f) $t_{t}=0 \mathrm{~s}$; (g) $t_{t}=164 \mathrm{~s}$; (h) $t_{t}=276 \mathrm{~s}$; (i) thawed.

described below. At a high freezing rate, the ice front becomes dendritic, but since the rate of advance reached $0.43 \mathrm{~m} \mathrm{~d}^{-1}$, faster than typical for the natural freezing environment, the discussion herein is limited to a flat ice front only. Tao et al. (2005) demonstrated that not only dendritic ice, but also a planar ice front, could fragment a wastewater-sludge floc.

Initially, the floc was far from the flat ice front (Fig. 2a). The original floc 1 had a loose structure with maximum sizes along its two principal axes of $1.92 \mathrm{~mm}$ (vertical length) and $2.14 \mathrm{~mm}$ (horizontal width). When the ice front moved closer to the floc, it remained flat. This motion differs from that of a PS sphere (Tao et al., 2004), approaching which the ice front concaved downward because the PS sphere had a much lower thermal conductivity than the ice (Casses and Azouni, 1993). The effective thermal conductivity of the floc interior should thus be similar to that of water.

Before the floc had touched the ice front, the beam was negligibly deflected (Fig. 2a). When the ice front came into contact with the floc $\left(t_{f}=24 \mathrm{~s}\right.$, Fig. 2b), the floc and the beam were pushed upward (Fig. 2c and d). Bubbles of size $35-500 \mu \mathrm{m}$ formed and grew at the ice-water interface as the floc froze. Meanwhile, the floc was elongated. At $t_{f}>427 \mathrm{~s}$, the ice completely trapped the floc. A comparison with the original floc
(Fig. 2a) showed that the completely frozen floc (Fig. 2e) had a $41 \%$ greater vertical length $(1.92-3.25 \mathrm{~mm})$, and a $31 \%$ smaller width $(2.14-1.48 \mathrm{~mm})$.

The testing section was extracted from the freezing pool in the thawing stage. The part of floc 1 that was elongated by the frozen ice then "contracted back" to a less-elongated shape during thawing (Fig. 2f-i). However, the original structure of the thawed floc could not be restored. Comparing Fig. 2a with $i$ showed that the freezing and thawing increased the vertical length of floc 1 by $21 \%(1.92-2.33 \mathrm{~mm})$, and reduced its width by $2 \%(2.14-2.19 \mathrm{~mm})$. The original shape of the floc could not be restored, so the floc's interior is visco-elastic. Glasgow (2003) also noted that his kaolin-polymer floc relaxed when compressed, exhibiting visco-elasticity. This characteristic substantially influences the force exerted on the floc during freezing (discussed below).

The global structure of the floc interior was looser than the original structure after freezing and thawing. The final equilibrium position of the beam was $h_{f}$ higher than that in Fig. 2a. When the floc (and the bubbles) were removed from the beam, the original position of the beam could be restored, indicating that the deflection $h_{f}$ was caused by the buoyant force associated with the attached bubbles, and the vertical deformation of 

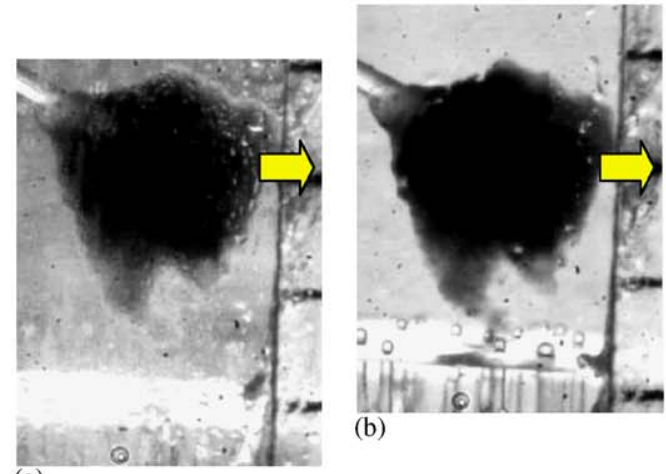

(b)

(a)

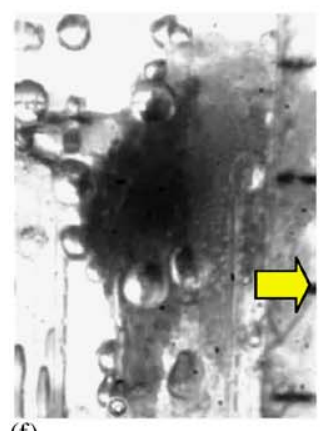

(f)

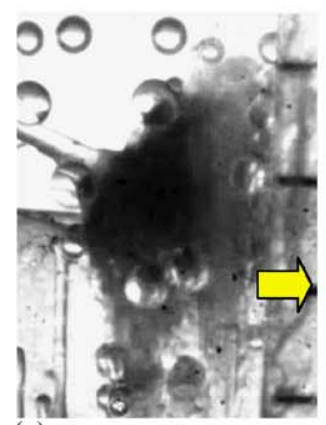

(g)

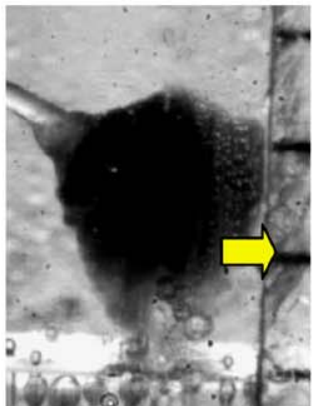

(c)

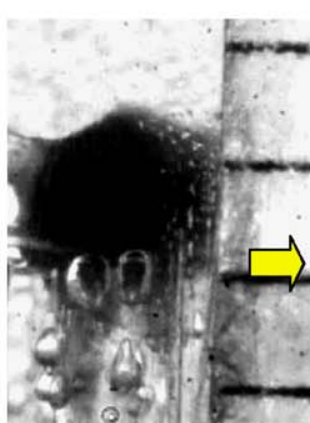

(d)

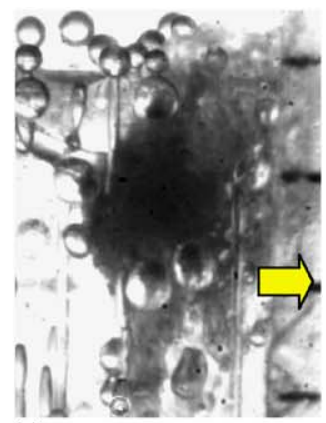

(e)

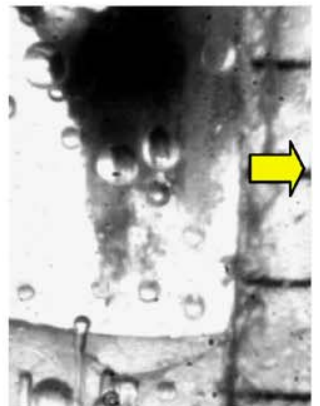

(i)

Fig. 3. The freezing-thawing test of floc 2. $V_{f}=8 \mu \mathrm{m} \mathrm{s}^{-1}$. The arrows indicate the same vertical position in the test: (a) $t_{f}=0 \mathrm{~s}$; (b) $t_{f}=48 \mathrm{~s}$; (c) $t_{f}=148 \mathrm{~s}$; (d) $t_{f}=452 \mathrm{~s}$; (e) frozen; (f) $t_{t}=88 \mathrm{~s}$; (g) $t_{t}=256 \mathrm{~s}$; (h) $t_{t}=336 \mathrm{~s}$; (i) thawed.

the beam detected in the freezing and thawing test was within the linear elastic regime.

Fig. 3 depicts the freezing and thawing test for floc 2 at a freezing rate of $8.0 \mu \mathrm{m} \mathrm{s}^{-1}$; the black scale bars represent $1 \mathrm{~mm}$. All the experimental results resemble those plotted in Fig. 2, despite a few differences. Firstly, more bubbles were formed during this freezing test. Following thawing, the attached bubbles resulted in a rather large $h_{f}$. In fact, the beam with thawed flocs moved upward rather than downward in this test. Secondly, a comparison with the floc 1 test reveals that the freezing stage for floc 2 is associated with a much smaller elongation of the floc body. Meanwhile, the shape of the thawing floc was only partially restored. Restated, the interior of floc 2 was less "elastic" than that of floc 1. Although the two flocs were collected from the same batch of sludge, their visco-elastic characteristics differed.

\subsection{Measuring force}

The arrows in Figs. 2 and 3 indicate the reference points during the tests. The deflection of beam $(Y)$ could thus be estimated, from which the normal force exerted by the beam on the floc could be calculated using Hooke's law. Figs. 4

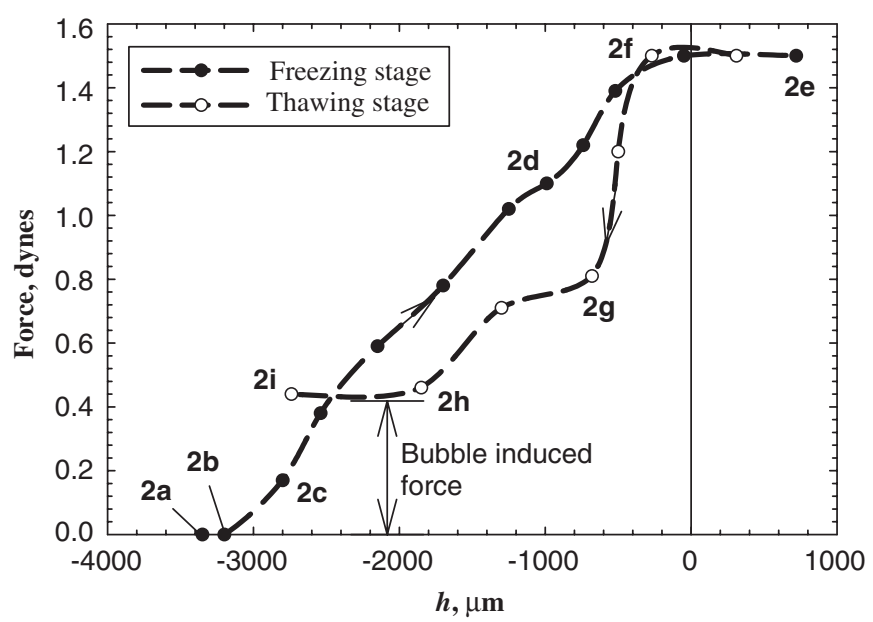

Fig. 4. The force- $h$ curves for the freeze-thaw cycle. Corresponding to the data in Fig. 2. $h$ depicted the distance of the moving ice front and the tip of the beam. Symbol " $2 X$ " indicates that the force was estimated corresponding to the image revealed in Fig. $2 X$.

and 5 plot the forces exerted by the beam on the floc during the freezing and thawing tests as displayed in Figs. 2 and 3, respectively. 


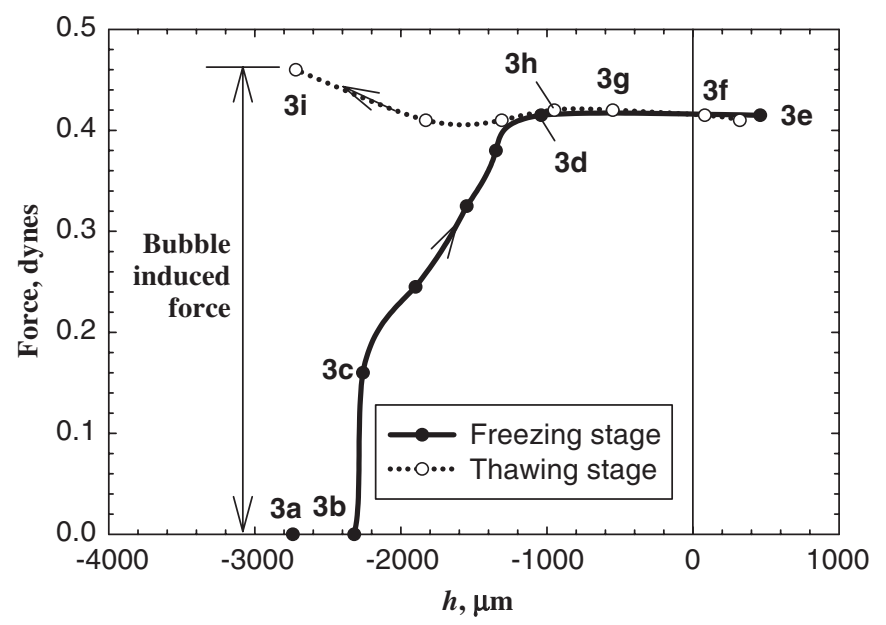

Fig. 5. The force- $h$ curves for the freeze-thaw cycle. Corresponding to the data in Fig. 3. $h$ depicted the distance of the moving ice front and the tip of the beam. Symbol " $3 X$ " indicates that the force was estimated corresponding to the image revealed in Fig. $3 X$.

When the ice moved toward floc 1 , no detectable force was exerted by the adopted beam before the bubble touched the surface of the ice (Fig. 2b and c). This observation revealed that the fluid flow pushed ahead by the moving ice front caused negligible hydrodynamic drag on the floc/bubble. The force became detectable only if the floc (and the bubbles) touched the ice front (Fig. 2c). The force increased almost linearly, before the interface reached the beam (Fig. 2e, $h=0$ ), reaching a plateau of $1.50 \times 10^{-5} \mathrm{~N}$.

During thawing, the force exerted on the floc fell accordingly. The original shape of the floc could not be restored after thawing, and the bubbles attached on the floc influence the buoyant weight of floc, so the force- $h$ curves exhibited hysteresis. The buoyancy force exerted by the attached bubbles on the thawed floc was approximately $4.4 \times 10^{-6} \mathrm{~N}$ (Fig. $2 \mathrm{i}$ ). The maximum force of $1.5 \times 10^{-5} \mathrm{~N}$ detected during freezing, was hence not totally attributable to the buoyancy caused by the bubbles.

When the ice moved toward floc 2 , the force $-h$ curves also exhibited hysteresis with a maximum force of only $4.2 \times 10^{-6} \mathrm{~N}$ (Fig. 5). This value is $28 \%$ of that of floc 1 . Following thawing, most bubbles attached to the floc remained undetached, yielding a final buoyancy force of $4.6 \times 10^{-6} \mathrm{~N}$.

\subsection{Action of force on untrapped floc}

The force balance on the floc (with bubbles) above the ice front is given as follows (Tao et al., 2004):

$F_{\mu}+F_{s}=F_{d}+F_{b}$,

where $F_{\mu}, F_{s}, F_{d}$ and $F_{b}$ are the drag force exerted by the fluid pushed ahead by the growing ice front, the elastic force exerted by the beam subtracted from the floc's buoyant weight, the disjoining force between the ice front and the floc due to the non-retarding van der Waals interaction, and the force exerted by the ice front and the part of the floc that is trapped in the ice, respectively. As Tao et al. (2004) estimated, the drag force exerted by the fluid $\left(F_{\mu}\right)$ and the disjoining force $\left(F_{d}\right)$ exerted by the ice on the floc are much lower than the elastic force $F_{S}$. This approximation also applies after the ice has engulfed part of the floc. When the unfrozen part of the floc is treated as the system in the force balance calculation, the bottom of the system is firmly fixed by the ice front, so

$F_{s}=E Y \approx F_{b}$

The force measured by the elastic beam approximates that exerted by the ice front on the floc.

In most natural processes or some industrial applications, the dissolved gas concentration in water is high. During freezing, the dissolved gas is expelled and concentrated ahead of the ice front because of the large difference between its solubilities in the water and ice phases. The experimental observations showed that the advancing ice was initially pushed ahead of the floc before any entrapment could occur. For example, all of floc 1 was noted to move with the beam and the ice front upward without entrapment to the stage presented in Fig. 2c. During this period, many bubbles were formed beneath and around the floc. The force exerted by the ice front on the untrapped floc 1 is estimated to be $1.8 \times 10^{-6} \mathrm{~N}$ (2c in Fig. 4). Similarly, floc 2 was noted to move ahead of the ice front without entrapment up to the stage presented in Fig. 3c, yielding an exerted force of $1.6 \times$ $10^{-6} \mathrm{~N}$ (Fig. 5). Tao et al. (2004) concluded that once the bubble was heterogeneously nucleated on the bottom of the sphere, its development controlled the force field on the sphere with a maximum force of $2.42 \times 10^{-6} \mathrm{~N}$ when a bubble was present under the sphere, whose value was close to that noted in the present floc freezing. This similarity may not be a coincidence, because bubbles are always formed during floc freezing, and the interaction between the ice front and a gas bubble may simply control the engulfment process, independently of whether the foreign particle is a PS sphere or a sludge floc. This action produces a pushing ahead force of $1.6-2.5 \times 10^{-6} \mathrm{~N}$ under the current experimental conditions.

This maximum force exerted by the ice front has practical significance: if the foreign particle could not resist this force (for example, $1.6-1.8 \times 10^{-6} \mathrm{~N}$ in this test), it would be repulsed with an acceleration determined by the particle mass and the fluid viscosity until reaching the terminal velocity. In such a case, whether or not the particle is entrapped in the growing ice front depends on the competition between the advancement of the ice front and the terminal velocity of the particle. In response to the same repulsive force exerted by the growing ice, a wastewater-sludge floc should have a higher acceleration than a similarly sized PS sphere with a lower effective density. However, the irregular shape of the former generates a higher drag force during acceleration than that of the latter. For the activated-sludge floc, the PS sphere is more easily trapped by the advancing ice front, based on the force balance considerations.

\subsection{Shape of floc during freezing}

Tao et al. (2004) established that the force curve of the PS sphere freezing test plateaued when the ice had engulfed $16 \%$ 


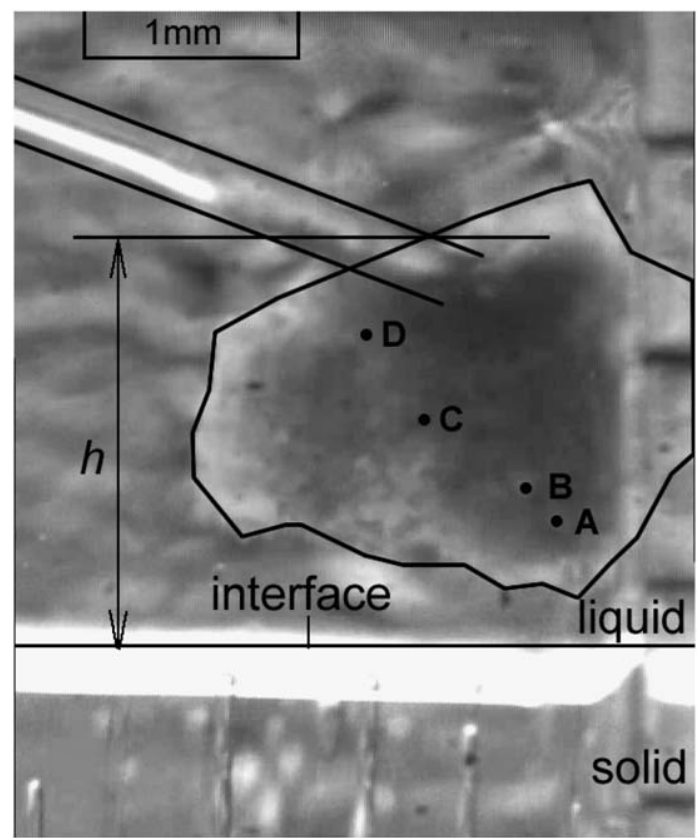

Fig. 6. The reference points on sludge floc 1 during freezing.

of the sphere's volume. However, the corresponding force associated with the freezing of the floc rose continuously throughout freezing (Figs. 4 and 5). Unlike a rigid particle, the floc was loose and compact. Several points (for example, A-D denoted in Fig. 6) on the image of original floc 1 were used to track the deformation of the floc during freezing and thawing. For instance, $h=1580 \mu \mathrm{m}$ for the unfrozen floc $1\left(L_{0}\right)$ and the vertical distance between point $B$ and the beam was $520 \mu \mathrm{m}$ $\left(L_{B 0}\right)$. In subsequent freezing, the ice continuously engulfed the floc, and a part of the floc inside the ice layer was pulled apart; the part above the ice was compressed. At $t_{f}=285 \mathrm{~s}$, point $B$ was just trapped by the ice; the corresponding lengths above and beneath the ice front were measured to be $740 \mu \mathrm{m}$ $\left(L_{B U h}\right)$ and $1620 \mu \mathrm{m}\left(L_{B F h}\right)$, respectively (Fig. 2d). During the freezing stage presented in Fig. $2 \mathrm{~b}-\mathrm{d}$, the floc's length below point $B$ increased from 520 to $1620 \mu \mathrm{m}$, or by $212 \%$. The floc's length between point $B$ and the beam fell from 1060 to $740 \mu \mathrm{m}$ or by $30.2 \%$. The corresponding force exerted by the beam (also the force exerted by the ice given by Eq. (2)) was $1.11 \times 10^{-5} \mathrm{~N}$. Based on the definition of an elastic coefficient for a sludge floc, $F_{S}=k_{U}\left(\left(L_{0}-L_{B 0}\right)-L_{B U h}\right)$, the coefficient $k_{U}$ is estimated to be $0.031 \mathrm{~N} \mathrm{~m}^{-1}$ for the unfrozen part of sludge floc 1 at point $B$. Also, a similar elongation coefficient can be defined as the ease with which a frozen section can be pulled apart by the ice front, $F_{S}=k_{F}\left(L_{B F h}-L_{B 0}\right)$. The coefficient $k_{F}$ is $0.0089 \mathrm{~N} \mathrm{~m}^{-1}$ for the frozen part of sludge floc 1. The unfrozen part of floc is much "stiffer" than the frozen part, possibly because of the direct action of ice on the trapped bubbles and the floc network's facilitating the pulling apart of the frozen part.

At $t_{f}=352 \mathrm{~s}$, point $C$ was just trapped by ice (plot not shown); the corresponding lengths above and under the ice fronts were 190 and $2360 \mu \mathrm{m}$, respectively. Restated, during the freezing stage shown in Fig. $2 \mathrm{~b}-\mathrm{d}$, the length of the section below point $C$ increased from 740 to $2360 \mu \mathrm{m}$, or by $219 \%$. The length of the section between point $C$ and the beam fell from 840 to $190 \mu \mathrm{m}$ or by $77.4 \%$. The corresponding force was $1.25 \times 10^{-5} \mathrm{~N}$. The coefficient $k_{U}$ for the unfrozen part is estimated to be $0.019 \mathrm{~N} \mathrm{~m}^{-1}$, and $k_{F}$ for the frozen part of the sludge floc 1 is $0.0077 \mathrm{~N} \mathrm{~m}^{-1}$ at point $C$. Based on the shape deformation detected by the tracking points $B$ and $C$, the mean $k_{U}$ and $k_{F}$ for floc 1 are estimated to be 0.025 and $0.0083 \mathrm{~N} \mathrm{~m}^{-1}$, respectively.

Similar procedures are adopted to estimate the corresponding values for floc 2 . The average $k_{U}$ and $k_{F}$ are $0.0063 \mathrm{~N} \mathrm{~m}^{-1}$ and $0.0030 \mathrm{~N} \mathrm{~m}^{-1}$, respectively. The interior of floc 1 was stiffer as measured by the elasticity $k_{U}$ than that of floc 2 . A floc with a stiff interior is difficult to pull apart, as evidenced by the larger $k_{F}$ for floc 1 than for floc 2 .

Matsuo and Unno (1981) studied the strength of alum flocs with a diameter of $300 \mu \mathrm{m}$, and Glasgow and Hsu (1982) studied the strength of kaolin flocs with a diameter of around $2200 \mu \mathrm{m}$. The strength of these inorganic flocs was smaller than that of the activated-sludge flocs studied herein, probably because biological flocs typically have filamentous bacteria as their backbone and microbially secreted EPS as their adhesive matrix, enhancing the strength (Droppo, 2004).

After the advancing ice had engulfed a part of the floc, the volume expansion of the latter pulled apart the network and compressed the volume of the bubbles associated with the floc, because of the volumic expansion of ice. This particular part of the floc was axially elongated and then fixed in the frozen layer; the accumulated force was pushed upward. This process was repeated during freezing. The engulfment-pulling apart action must cause considerable local compression and a shear force that is probably responsible for both the change in floc structure and the release of ECP from wastewater sludge following freezing and thawing.

\section{Conclusions}

This work applied the uni-directional freezing apparatus used by Tao et al. (2004) to measure the deflection of the cantilevered beam that was connected to two flocculated wastewater-sludge flocs and the change in their shapes ahead of an approaching ice front. The force exerted on the floc and the elasticity of the floc were estimated from the beam deflection and the shape deformation, respectively, based on Hooke's Law.

During the engulfment of the floc, the floc was elongated by $31-41 \%$ over the length of the original floc. During thawing, the floc's shape was partially restored. Therefore, the floc's interior is visco-elastic, as demonstrated by its stress-strain relation. The global structure of the interior of the floc was looser than that of original floc, following freezing and thawing. Moreover, although the two flocs were collected from a single source, their visco-elastic characteristics differed substantially.

The maximum force exerted by an approaching ice front on the floc ranged from 1.6 to $1.8 \times 10^{-6} \mathrm{~N}$. Whether or not the floc is entrapped in the growing ice front depends on the competition between the advancement of the ice front and that of the floc. 
The irregular shapes of the tested flocs are responsible for they having a higher drag than PS spheres of the same size, so they are more easily engulfed by the ice.

Some reference points on the floc image were tracked in the tests to quantify the shape deformation of the sludge floc during freezing and thawing. Based on the proportionality constant between exerted force and the change in floc length, the interior elasticity of the flocs was estimated to be $0.0063-0.025 \mathrm{~N} \mathrm{~m}^{-1}$, and the elongation coefficient was $0.0030-0.0089 \mathrm{~N} \mathrm{~m}^{-1}$.

\section{Notation}

E

$F_{b} \quad$ force exerted by the ice front and the part of the floc trapped in ice, $\mathrm{N}$

$F_{d} \quad$ disjoining force between the ice front and the floc, $\mathrm{N}$

$F_{S} \quad$ elastic force exerted by the beam subtracted from the floc's buoyant weight, $\mathrm{N}$

$F_{\mu} \quad$ drag force exerted by the fluid pushed ahead by the growing ice front, $\mathrm{N}$

$h \quad$ ice interface-beam distance, $\mathrm{m}$

$h_{f} \quad$ ice-interface-beam distance for the thawed floc, $\mathrm{m}$

$k_{F} \quad$ elongation coefficient, $\mathrm{N} \mathrm{m}^{-1}$

$k_{U} \quad$ elastic coefficient, $\mathrm{N} \mathrm{m}^{-1}$

$L_{0} \quad$ vertical length of the unfrozen floc, $m$

$L_{B 0} \quad$ vertical distance between point $B$ and the beam, m

$L_{B F h} \quad$ vertical length of the floc body below point $B$ when the ice just engulfed point $B, \mathrm{~m}$

$L_{B U h} \quad$ vertical length of the floc body above point $B$ when the ice just engulfed point $B, \mathrm{~m}$

$t_{f} \quad$ freezing time, $\mathrm{s}$

$t_{t} \quad$ thawing time, $\mathrm{s}$

$Y \quad$ deflection of the beam, $m$

\section{Acknowledgments}

This research is supported by the National Natural Science Foundation of China (Contract no. 50136020) and by the National Science Council. T. Tao thank the National Taiwan University for inviting him as an exchange student during November 2003-February 2004.

\section{References}

Brehm-Stecher, B.F., Johnson, E.A., 2004. Single-cell microbiology: tools, technologies, and applications. Microbiology and Molecular Biology Review 68, 538-559.

Casses, P., Azouni, M.A., 1993. Thermal effects on the shape of a solidifying interface near a foreign particle. Journal of Crystal Growth 130, 13-20.

Chang, M.R., Chiang, L.I., Lee, D.J., Liu, J.C., Wu, N.M., Chen, W.C., Hsu, B.M., 2004. Conditioning of wastewater sludge of science-based industrial park using freezing and thawing. Journal of Environmental Engineering 130, 1552-1555.

Chen, L.C., Chian, C.Y., Yen, P.S., Chu, C.P., Lee, D.J., 2001. High-speed sludge freezing. Water Research 35, 3502-3507.

Chian, C.Y., Chen, L.C., Yen, P.S., Chu, C.P., Lee, D.J., Lee, S.F., Chen, T.H., 2002. Sludge freezing at a high speed. Drying Technology 20, 1019-1033.
Chu, C.P., Feng, W.H., Tsai, Y.H., Lee, D.J., 1997. Uni-directional freezing of waste activated sludge: the presence of sodium chloride. Environmental Science \& Technology 31, 1512-1517.

Chu, C.P., Feng, W.H., Chang, B.V., Lee, D.J., 1999. Reduction in microbial density level through freezing and thawing. Water Research 33, 3532-3535.

Droppo, I.G., 2004. Structural controls on floc strength and transport. Canadian Journal of Civil Engineers 31, 569-578.

Ezekwo, G., Tong, H.M., Gryte, C.C., 1980. On the mechanism of dewatering colloidal aqueous solutions by freeze-thaw processes. Water Research 14, 1079-1088.

Garvin, J.W., Udaykumar, H.S., 2003. Particle-solidification front dynamics using a fully coupled approach, part II: comparison of drag expression. Journal of Crystal Growth 252, 467-479.

Glasgow, L.A., 2003. Deformation of individual aggregates and flocs. Journal of Dispersion Science and Technology 24, 715-720.

Glasgow, L.A., Hsu, J.P., 1982. An experimental study of floc strength. A.I.Ch.E. Journal 28, 779-785.

Halde, R., 1980. Concentration of impurities by progressive freezing. Water Research 14, 575-580.

Han, Q., Hunt, J.D., 1995. Particle pushing: critical flow rate required to put particles into motion. Journal of Crystal Growth 152, 221-227.

Hellstrom, D., Kvarnstrom, E., 1997a. Natural sludge dewatering. 1. Combination of freezing, thawing, and drying as dewatering methods. Journal of Cold Regions Engineering 11, 1-14.

Hellstrom, D., Kvarnstrom, E., 1997b. Natural sludge dewatering. 1. Thawingdrying process in full-scale sludge freezing ditches. Journal of Cold Regions Engineering 11, 15-29.

Hong, S.G., Young, Y.D., Chen, G.W., Chang, I.L., Hung, W.T., Lee, D.J., 1995. Freeze/thaw treatment on waste activated sludge: an FTIR spectroscopic study. Journal of Environmental Science and Health A 30, 1717-1724.

Hung, W.T., Chang, I.L., Lin, W.W., Lee, D.J., 1996. Uni-directional freezing of waste activated sludges: effects of freezing speed. Environmental Science \& Technology 30, 2391-2396.

Hung, W.T., Feng, W.H., Tsai, I.H., Lee, D.J., Hong, S.G., 1997. Unidirectional freezing of waste activated sludge: vertical freezing versus radial freezing. Water Research 31, 2219-2228.

Jean, D.S., Lee, D.J., 1999. Effects of electrolyte and curing on freeze/thaw treatment of ferric hydroxide sludge. Colloid and Surface A 162, 285-288.

Jean, D.S., Lee, D.J., Wu, J.C.S., 1999. Separating oil from oily sludge by freezing and thawing. Water Research 33, 1756-1759.

Jean, D.S., Chu, C.P., Lee, D.J., 2000. Effects of electrolyte and curing time on freeze/thaw treatment of sludge. Water Research 34, 1577-1583.

Jean, D.S., Chu, C.P., Lee, D.J., 2001. Freeze/thaw treatment on oily sludge from oil refinery plant. Separation Science and Technology 36, 2733-2746.

Kawasaki, K., Matsuda, A., 1993. Freezing and thawing of excess activated sludge to improve the solid liquid separation characteristics. In: The Sixth World Filtration Congress, Nagoya, Japan, pp. 865-868.

Kawasaki, K., Matsuda, A., 1995. Effect of dissolved solid concentration on freezing and thawing treatment of excess activated-sludge. Kagaku Kogaku Ronbunshu 21, 859-865.

Kawasaki, K., Matsuda, A., Mizukawa, Y., 1991. Compression characteristics of excess activated sludges treated by freezing-and-thawing process. Journal of Chemical Engineering of Japan 24, 743-748.

Knocke, W.R., Trahem, P., 1989. Freeze-thaw conditioning of chemical and biological sludges. Water Research 23, 35-42.

Lai, C.K., Chen, G.H., Lo, M.C., 2004. Salinity effect on freeze/thaw conditioning of activated sludge with and without chemical addition. Separation \& Purification Technology 34, 155-164.

Lee, D.J., 1994. Floc structure and bound water content in excess activated sludges. Journal of Chinese Institute of Chemical Engineers 25, 201-207.

Lee, D.J., Hsu, Y.H., 1994. Fast freeze/thaw treatment on activated sludge: floc structure and sludge dewaterability. Environmental Science \& Technology 28, 1444-1449.

Lee, D.J., Hsu, Y.H., 1995. Measurement of bound water in sludges: a comparative study. Water Environment Research 67, 310-317. 
Lo, I.M.C., Lai, K.C.K., Chen, G.H., 2001. Salinity effect on mechanical dewatering of sludge with and without chemical conditioning. Environmental Science \& Technology 35, 4691-4696.

Logsdon, G.S., Edgerley Jr., E., 1971. Sludge dewatering by freezing. Journal of American Water Works Association 63, 734-740.

Martel, C.J., 1989a. Dewaterability of freeze-thaw conditioned sludges. Journal of Water Pollution Control Federation 61, 237-241.

Martel, C.J., 1989b. Development and design of sludge freezing bed. Journal of Environmental Engineering 115, 799-808.

Martel, C.J., 2000. Influence of dissolved solids on the mechanism of freeze-thaw conditioning. Water Research 34, 657-662.

Martel, C.J., Diener, C.J., 1991. A pilot-scale study of alum sludge dewatering in a freezing bed. Journal of American Water Works Association 83, 51-55.

Matsuo, T., Unno, H., 1981. Forces acting on floc and strength of floc. Journal of Environmental Engineering 107, 527-545.

Ormeci, B., Vesilind, P.A., 2001. Effect of dissolved organic material and cations on freeze/thaw conditioning of activated and alum sludge. Water Research 35, 4299-4306.

Parker, P.J., Collins, A.G., Dempsey, J.P., 1998a. Alum residual floc interactions with an advancing ice/water interface. Journal of Environmental Engineering 124, 249-253.

Parker, P.J., Collins, A.G., Dempsey, J.P., 1998b. Effects of freezing rate, solids content, and curing time on freeze/thaw conditioning of water treatment residuals. Environmental Science \& Technology 124, 249-253.

Poppele, E.H., Hozalski, R.M., 2003. Micro-cantilever method for measuring the tensile strength of biofilms and microbial flocs. Journal of Microbiological Methods 55, 607-615.
Randall, C.W., Alikham, M.Z., Stephens, N.T., 1975. Waste activated-sludge conditioning by direct slurry freezing. Water Research 9, 917-925.

Sanin, F.D., Vesilind, P.A., Martel, C.J., 1994. Pathogen reduction capabilities of freeze/thaw sludge conditioning. Water Research 28, 2393-2398.

Tao, T., Peng, X.F., Lee, D.J., 2004. Force by gas bubble on foreign particle in front of freezing interface. Journal of Colloid and Interface Science 280, 409-416.

Tao, T., Peng, X.F., Lee, D.J., 2005. Fragmentation of wastewater sludge floc by planar ice front. Journal of Colloid and Interface Science 290, 298-301.

Uhlman, D.R., Chalmers, B., Jackson, K.A., 1964. Interaction between particles and a solid-liquid interface. Journal of Applied Physics 35, 2986-2992.

Vesilind, P.A., 1990. Sludge freezing in shallow layers. Journal of Environmental Engineering 116, 646-650.

Vesilind, P.A., Martel, C.J., 1990. Freezing of water and wastewater sludges. Journal of Environmental Engineering 116, 854-862.

Vesilind, P.A., Wallinmaa, S., Martel, C.J., 1991a. Freeze-thaw sludge conditioning and double layer compression. Canadian Journal of Civil Engineering 18, 1078-1083.

Vesilind, P.A., Hung, W., Martel, C.J., 1991b. Agitation and filterability of freeze/thawed sludge. Journal of Cold Regions Engineering 5, 77-83.

Wang, Q.H., Fujisaki, K., Ohsumi, Y., Ogawa, H.I., 2001. Enhancement of dewaterability of thickened waste activated sludge by freezing and thawing treatment. Journal of Environmental Science and Health A 36, 1361-1371.

Yeung, A.K.C., Pelton, R., 1996. Micromechanics: a new approach to studying the strength and breakup of flocs. Journal of Colloid and Interface Science 184, 579-585. 